\title{
Divergence in the Expression of Molecular Markers of Neuronal Activation in the Parvocellular Paraventricular Nucleus of the Hypothalamus Evoked by Alcohol Administration via Different Routes
}

\author{
Kathleen M. Ogilvie, Soon Lee, and Catherine Rivier \\ The Clayton Foundation Laboratories for Peptide Biology, The Salk Institute for Biological Studies, \\ La Jolla, California 92037
}

Immediate early gene (IEG) expression has been routinely used by neuroscientists as an index of neuronal activation. In the case of the hypothalamic-pituitary-adrenal axis, induction of c-fos and/or NGFI-B mRNAs in the parvocellular paraventricular nucleus ( $p P V N$ ) has been documented after a variety of stimuli that increase adrenocorticotropin (ACTH) in the systemic circulation. However, the functional relationship between expression of IEGs and transcription of the genes for the ACTH secretagogues corticotropin-releasing factor (CRF) and arginine vasopressin (AVP) is not clear. While investigating the neuroendocrine correlates of alcohol administration via different routes (intraperitoneal vs intragastric), we noted a difference in the time course of NGFI-B mRNA expression in the pPVN, despite comparable dynamics in ACTH secretion. By comparing the temporal cascade of transcriptional events in vivo after alcohol injection via either route, we sought to determine functional relationships between IEGs and the induction of CRF and
AVP heteronuclear RNAs (hnRNAs). One advantage of our paradigm is the use of the same stimulus (systemic alcohol injection) in which access to the CNS does not differ between the groups to be compared. Intraperitoneal administration of the drug resulted in significant increases in c-fos mRNA, Fos protein, CRF hnRNA, and AVP hnRNA. In contrast, intragastric treatment evoked a brief, modest elevation in c-fos mRNA and Fos protein, increased AVP hnRNA, and caused no detectable change in CRF hnRNA. These data indicate that robust increases in CRF hnRNA are closely linked to full expression of c-fos mRNA and Fos protein. In addition, the expression of NGFI-B after both routes of administration is indicative of cellular activation within the pPVN in parallel with secretion of ACTH.

Key words: hypothalamic-pituitary-adrenal axis; adrenocorticotropin; corticotropin-releasing hormone; arginine vasopressin; c-fos mRNA; Fos protein; NGFI-B mRNA
Secretion of adrenocorticotropin (ACTH) is largely regulated by neurons localized in the parvocellular paraventricular nucleus (pPVN) (Antoni, 1986) that synthesize corticotropin-releasing factor (CRF) and arginine vasopressin (AVP) (Swanson and Sawchenko, 1983). The essential role of these peptides in controlling the response of the hypothalamic-pituitary-adrenal (HPA) axis (Rivier and Plotsky, 1986) extends to alcohol administration. Alcohol acutely increases ACTH levels in rats (Rivier, 1996), a response that is blocked by immunoneutralization of CRF (Rivier et al., 1984) and attenuated by immunoneutralization of AVP (Ogilvie et al., 1997b). A functional relationship between CRF neurons and the HPA response to alcohol is corroborated by the ability of the drug to activate neurons in the pPVN.

Examination of immediate early gene (IEG) expression (e.g., c-fos and NGFI-B mRNAs) has been widely used as a marker of neuronal activation (Sagar et al., 1988; Dragunow and Faull, 1989; Watson and Milbrandt, 1989; Doucet et al., 1990; Morgan and Curran, 1991; Hoffman et al., 1993). Investigation of Fos

\footnotetext{
Received Oct. 15, 1997; revised March 6, 1998; accepted March 13, 1998.

We are grateful to Drs. T. Sherman, I. Verma, and S. Watson for gifts of reagents and to W. Kau, P. Senarith, J. Lacsamana, J. Woo, and Y. Haas for technical assistance.

Correspondence should be addressed to Dr. Catherine Rivier, The Clayton Foundation Laboratories for Peptide Biology, The Salk Institute for Biological Studies, 10010 North Torrey Pines Road, La Jolla, CA 92037.

Dr. Ogilvie's present address: Department of Pharmacology, Ligand Pharmaceuticals, 10275 Science Center Drive, San Diego, CA 92121.

Copyright (C) 1998 Society for Neuroscience 0270-6474/98/184344-09\$05.00/0
}

and/or NGFI-B mRNAs has been valuable in the study of PVN activation by a variety of stimuli e.g., restraint or foot shock stress (Imaki et al., 1992; Rivest and Rivier, 1994), immune challenge (Rivest et al., 1992; Chan et al., 1993; Day and Akil, 1996), and alcohol intoxication (Chang et al., 1994; Zoeller and Fletcher, 1994; Rivier and Lee, 1995; Ryabinin et al., 1997). Messenger RNAs for both c-fos and NGFI-B are induced by activation of extracellular receptors followed by translation to their respective proteins, which bind to consensus sequences on target DNAs, regulating ensuing gene expression. For Fos, heterodimerization with jun is required for binding to the target DNA (termed the AP1 site) (Morgan and Curran, 1989, 1991). A DNA binding site for NGFI-B, called NGFI-B response element (NBRE), has also been described (Wilson et al., 1991). Although both CRF and c-fos mRNAs are increased by various stressors, the CRF gene promoter lacks an AP1 site. However, putative NBREs are present in the promoters of both the rat CRF and AVP genes (Mohr and Richter, 1990; Wilson et al., 1991; Chan et al., 1993). This suggests a mechanism for direct interaction between NGFI-B and the genes that code for these peptides, whereas a similar functional relationship between Fos protein and CRF transcription cannot be hypothesized (Chan et al., 1993).

Because unselected laboratory rodents do not spontaneously consume alcohol, the study of the neuroendocrine effects of this drug relies on its forceful administration. Although we have used intraperitoneal cannulae in the past, we recently adopted intra- 
gastric cannulae that allow for alcohol delivery into the stomach, because this latter route may be more relevant to human use of the drug. Previously, we reported that intraperitoneal or intragastric alcohol administration evoked comparable ACTH secretion, with peak levels occurring at $30 \mathrm{~min}$ and lasting $2 \mathrm{hr}$. Although both groups of rats given alcohol had high levels of NGFI-B mRNA, peak expression was observed $1 \mathrm{hr}$ after intraperitoneal treatment but $2 \mathrm{hr}$ after intragastric treatment (Ogilvie et al., 1997a). We sought to exploit this difference in time course to determine functional relationships between IEGs and the transcription of CRF and AVP. In particular, we were interested in determining whether the appearance of heteronuclear transcripts for CRF and AVP corresponded with more general indexes of neuronal stimulation, as indicated by the appearance of IEGs. Here, we extended our studies to include levels of c-fos mRNA and Fos protein as well as AVP and CRF intronic sequences [heteronuclear RNAs (hnRNAs)].

\section{MATERIALS AND METHODS}

Animals. Male Holtzman rats weighing 180-200 gm were purchased from Harlan Sprague Dawley (Indianapolis, IN) and were maintained in groups (three to four rats per cage) on a $12 \mathrm{hr}$ light/dark cycle (lights on at 6:00 A.M.). Under halothane anesthesia, all animals were implanted with both intragastric and intraperitoneal cannulae 7-8 d before experimentation. This approach was used to ensure identical surgical procedures in all rats and to eliminate the possibility that differences in RNA expression might be, at least in part, attributable to the surgical process. Intragastric cannulae were constructed of polyethylene tubing (PE90) expanded twice, $\sim 5 \mathrm{~mm}$ apart, at the end inserted into the stomach. Using a dorsal approach, a small hole was cut in the skin and body musculature below the ribs on the rat's left side. The stomach was pulled through the opening, and a hole was made with spreader forceps in the fundus through which the cannula was inserted into the stomach. The cannula was sutured in place between the two bubbled parts of the cannula to retain the tip in the lumen of the stomach. With the aid of a trochar, the cannula was exteriorized through the body wall and passed under the skin to exit at the nape of the neck, where it was capped with a steel pin. Intraperitoneal cannulae were made of PE60 so that they could be distinguished from intragastric cannulae and placed as previously described (Ogilvie and Rivier, 1996). To prevent chewing of the exteriorized cannulae, animals were housed individually in plastic cages with pine bedding after surgery. All protocols were approved by the Salk Institute Institutional Animal Care and Use Committee.

Experimental protocol. On the day of an experiment, animals were removed to a soundproof room and their cannulae were extended with PE tubing connected to syringes containing sterile saline. Rats were housed individually in opaque buckets with pine shavings and left undisturbed for $3 \mathrm{hr}$. Beginning at 11:00 A.M. animals were injected with alcohol (see below) via either the intraperitoneal or intragastric cannula and killed 10-240 min later ( $n=5$ per group). Uninjected controls were killed throughout the experimental session and processed in parallel with treated animals. Previous work in our laboratory has shown that rats injected with the vehicle do not have upregulated levels of c-fos mRNA, Fos protein, NGFI-B mRNA, CRF hnRNA, or AVP hnRNA after either route of injection, intraperitoneal (Lee and Rivier, 1994; Rivier and Lee, 1996) or intragastric (Lee and Rivier, 1997). Samples were obtained from two different experiments conducted over $2 \mathrm{~d}$ in each case. Animals from each treatment group were collected each day. To kill animals and obtain brain tissue, rats were injected with an overdose of chloral hydrate $(35 \%$, $0.7 \mathrm{ml}$ ) via the intraperitoneal cannula. After the animals were unconscious, they were removed to a hood and transcardially perfused with saline followed by $4 \%$ paraformaldehyde and $0.1 \mathrm{~m}$ borate buffer. We have shown that this procedure does not alter basal mRNA levels of the signals measured here (Rivier and Lee, 1995, 1996). After brief postfixation in $4 \%$ paraformaldehyde buffer, brains were allowed to sink overnight in $10 \%$ sucrose and $4 \%$ paraformaldehyde buffer. The next day, tissues were cut frozen $(30 \mu \mathrm{m})$ on a sliding microtome and either placed in a cryoprotectant solution (50\% $0.1 \mathrm{~m} \mathrm{PBS,} 30 \%$ ethylene glycol, and $20 \%$ glycerol) and stored at $-20^{\circ} \mathrm{C}$ if they were intended for immunocytochemistry or placed in $4 \%$ paraformaldehyde and stored at $4^{\circ} \mathrm{C}$ for an additional $4 \mathrm{~d}$ if they were intended for in situ hybridization.
Tissues from the first replicate of this experiment were probed for NGFI-B mRNA, CRF hnRNA, and AVP hnRNA. Sections from the second replicate were analyzed for Fos protein, c-fos mRNA, and CRF hnRNA.

Alcohol treatment. Alcohol was given at a dose of $3 \mathrm{gm} / \mathrm{kg}$ of body weight in a solution of saline containing $10 \%$ lidocaine to minimize discomfort. We chose this dose of alcohol, which produces a moderate degree of intoxication, based on preliminary experiments in which changes in expression of CRF and AVP mRNAs in the PVN were found to be most consistent and robust after intraperitoneal administration (Lee and Rivier, 1998). As previously reported, this dose results in blood alcohol levels (BALs) that peak within 15 min of administration via either route (intraperitoneal, $0.488 \pm 0.081 \% \mathrm{w} / \mathrm{v}$; intragastric, $0.232 \pm$ $0.054 \% \mathrm{w} / \mathrm{v}$ ) and remain elevated for at least $3 \mathrm{hr}$ (at $180 \mathrm{~min}$ : intraperitoneal, $0.167 \pm 0.022 \% \mathrm{w} / \mathrm{v}$; intragastric, $0.181 \pm 0.057 \% \mathrm{w} / \mathrm{v})($ Ogilvie et al., 1997a). Alcohol was diluted to $17-20 \%$ because its concentration is an important factor in absorption of the drug through the gastric mucosa (Kinoshita et al., 1995; Maier et al., 1995). Because of the large volumes injected (up to $6 \mathrm{ml}$ ), injections were given over 2-3 min.

Immunocytochemistry. Because of the number of samples generated, immunocytochemistry was done in batches. To control for variation between these cohorts, samples were processed such that half of each group (time and injection route) were subject to immunocytochemistry at the same time.

Immunocytochemistry for Fos was performed as previously described (Ogilvie and Rivier, 1997). Briefly, nonspecific binding was blocked by treatment with normal goat serum (1:25) followed by incubation with primary antiserum (1:20,000 Ab5 generated to c-fos, Oncogene Sciences) for $36 \mathrm{hr}$ at $4^{\circ} \mathrm{C}$. After several washes with potassium PBS (KPBS), sections were incubated with biotinylated anti-rabbit $\gamma$-globulin for 45 min, washed, and incubated with horseradish peroxidase-avidin complex for $45 \mathrm{~min}$. To enhance the specificity of the reaction, sections were treated again with second antibody $(30 \mathrm{~min})$, washed, and incubated a second time with horseradish peroxidase-avidin complex (30 $\mathrm{min})$. Color product was formed by incubating with $\mathrm{DAB}$ and hydrogen peroxide with nickel intensification (black product). Sections were mounted on poly-L-lysine-coated slides, vacuum-dried overnight, dehydrated through an alcohol series, cleared in xylenes, and coverslipped with a mixture of distrene, tricresyl phosphate, and xylene (DPX) (13512, Electron Microscopy Sciences).

In situ hybridization. Protocols for riboprobe synthesis, hybridization, and autoradiography were adopted from those of Simmons et al. (1989) and are routinely performed in our laboratory. All solutions were treated with diethylpyrocarbonate and autoclaved to prevent degradation of RNA.

The pBluescript SK-1 vector (Stragene, La Jolla, CA) containing a 2.0 $\mathrm{kb} E c o$ RI fragment of rat c-fos cDNA (Dr. I. Verma, The Salk Institute, La Jolla, CA) was linearized with SmaI. The pGEM3 plasmid containing a $530 \mathrm{bp}$ fragment of CRF intron (Dr. S. Watson, University of Michigan, Ann Arbor, MI) and pGEM3 plasmid containing a $700 \mathrm{bp} P v u I I$ fragment of rat vasopressin gene fragment of intron I (Dr. T. Sherman, Georgetown University, Washington, DC) were linearized with HindIII. Radioactive cRNA copies were synthesized by incubation of $250 \mathrm{ng}$ of linearized plasmid in $6 \mathrm{mM} \mathrm{MgCl}_{2}, 36 \mathrm{~mm}$ Tris, $\mathrm{pH} 7.5,2 \mathrm{~mm}$ spermidine, $8 \mathrm{~mm}$ dithiothreithol, $25 \mathrm{mM}$ ATP, GTP, and CTP, $\left[\alpha^{-35}\right.$ S $]$ UTP or $\left[{ }^{33} \mathrm{P}\right] \mathrm{UTP}, 1 \mathrm{U}$ of RNasin (Promega, Madison, WI), and $10 \mathrm{U}$ of T7 (for c-fos, CRF intron, and AVP intron) for $60 \mathrm{~min}$ at $37^{\circ} \mathrm{C}$. Unincorporated nucleotides were removed using Quick-Spin columns (Boehringer Mannheim, Indianapolis, IN). A sense probe, of the same size as the corresponding antisense probe, was used as a control for nonspecific signal in some adjacent sections (negative control).

Before hybridization, tissue sections (every fifth section) were mounted onto gelatin- and poly-L-lysine-coated slides and dried under vacuum overnight, fixed (4\% paraformaldehyde, $30 \mathrm{~min}$ ), digested by proteinase K (catalog \#24568; Merck, Darmstadt, Germany; $10 \mu \mathrm{g} / \mathrm{ml}$ at $37^{\circ} \mathrm{C}$ for $\left.25 \mathrm{~min}\right)$, rinsed in triethylamine (0.1 M TEA, $\left.\mathrm{pH} 8.0\right)$, acetylated (25\% acetic anhydride in TEA), and dehydrated through an alcohol series $(50,70,100$, and $100 \%, 3 \mathrm{~min}$ each). After vacuum-drying, the c-fos, CRF intron, and AVP intron cRNA probes were applied to each slide in $90 \mu \mathrm{l}$ of hybridization mixture $\left[10^{7} \mathrm{cpm} / \mathrm{ml}, 10 \mathrm{~mm}\right.$ formamide, $36 \mathrm{~mm} \mathrm{NaCl}, 1.2 \mathrm{~mm}$ Tris HCl, $1.2 \mathrm{~mm}$ EDTA, $1 \times$ Denhardt's solution, $10 \%$ dextran sulfate, $0.5 \mathrm{mg} / \mathrm{ml}$ tRNA (catalog \#109541, Boehringer Mannheim), and $10 \mathrm{~mm}$ DTT] and sealed under a coverslip with DPX (13512, Electron Microscopy Sciences). After incubation at $60^{\circ} \mathrm{C}$ overnight, coverslips were removed, and sections were rinsed in four washes 
Table 1. Levels of pPVN and mPVN RNA after intraperitoneal and intragastric injection of alcohol

Time (min) after injection

\begin{tabular}{|c|c|c|c|c|c|c|}
\hline & \multicolumn{6}{|c|}{ Time (min) after injection } \\
\hline & 10 & 30 & 60 & 120 & 180 & 240 \\
\hline c-fos mRNA pPVN & \multicolumn{6}{|c|}{ route, $p=0.0027 ;$ time, $p=0.0124 ;$ route $\times$ time, $p=0.0050^{b}$} \\
\hline Intraperitoneal & $353.8 \pm 140.9^{a}$ & $1309.1 \pm 583.3$ & $3522.6 \pm 588.0$ & $3038.2 \pm 694.0$ & $955.0 \pm 250.0$ & $1143.5 \pm 0$ \\
\hline Intragastric & $767.6 \pm 108.4$ & $961.2 \pm 787.4$ & $323.5 \pm 172.5$ & $381.5 \pm 490.3$ & $70.0 \pm 165.3$ & $1259.4 \pm 547.6$ \\
\hline c-fos mRNA mPVN & \multicolumn{6}{|c|}{ route, $p=0.3881 ;$ time, $p=0.3414 ;$ route $\times$ time, $p=0.7323$} \\
\hline Intraperitoneal & $92.7 \pm 33.9$ & $353.9 \pm 206.3$ & $325.4 \pm 102.0$ & $499.7 \pm 153.4$ & $208.1 \pm 41.1$ & $221.7 \pm 0.00$ \\
\hline Intragastric & $298.0 \pm 54.6$ & $306.9 \pm 211.2$ & $143.5 \pm 83.0$ & $305.1 \pm 181.6$ & $87.2 \pm 15.8$ & $239.8 \pm 78.3$ \\
\hline AVP hnRNA pPVN & \multicolumn{6}{|c|}{ route, $p=0.0125 ;$ time, $p=0.0402 ;$ route $\times$ time, $p=0.6172$} \\
\hline Intraperitoneal & $\mathrm{ND}^{c}$ & $35.5 \pm 27.7$ & $83.9 \pm 19.9$ & $148.0 \pm 26.0$ & $161.3 \pm 45.3$ & $131.8 \pm 10.8$ \\
\hline Intragastric & ND & $106.2 \pm 23.2$ & $204.9 \pm 102.1$ & $296.0 \pm 103.7$ & $394.1 \pm 105.3$ & $357.1 \pm 113.7$ \\
\hline AVP hnRNA mPVN & \multicolumn{6}{|c|}{ route, $p=0.0003 ;$ time, $p=0.0126 ;$ route $\times$ time, $p=0.0048$} \\
\hline Intraperitoneal & ND & $308.2 \pm 121.3$ & $422.9 \pm 99.2$ & $704.6 \pm 167.7$ & $442.4 \pm 88.0$ & $477.3 \pm 179.7$ \\
\hline Intragastric & ND & $632.9 \pm 174.8$ & $948.8 \pm 232.9$ & $1245.7 \pm 284.8$ & $1819.5 \pm 131.3$ & $2333.7 \pm 608.8$ \\
\hline CRF hnRNA pPVN & \multicolumn{6}{|c|}{ route, $p=0.0060 ;$ time, $p=0.0002 ;$ route $\times$ time, $p=0.0001$} \\
\hline Intraperitoneal & $118.6 \pm 62.4$ & $209.4 \pm 68.2$ & $680.3 \pm 84.0$ & $61.3 \pm 32.4$ & $85.8 \pm 43.0$ & $129.2 \pm 129.2$ \\
\hline Intragastric & $157.6 \pm 84.5$ & $77.6 \pm 38.8$ & $74.5 \pm 42.3$ & $67.0 \pm 30.7$ & $66.7 \pm 49.3$ & $123.0 \pm 32.8$ \\
\hline CRF hnRNA mPVN & \multicolumn{6}{|c|}{ route, $p=0.0330 ;$ time, $p=0.0552 ;$ route $\times$ time, $p=0.1109$} \\
\hline Intraperitoneal & $242.8 \pm 158.2$ & $97.3 \pm 62.9$ & $488.7 \pm 117.8$ & $104.4 \pm 34.2$ & $202.4 \pm 35.8$ & $356.2 \pm 53.5$ \\
\hline Intragastric & $146.4 \pm 82.9$ & $139.3 \pm 75.0$ & $90.2 \pm 35.9$ & $58.6 \pm 47.4$ & $59.3 \pm 59.3$ & $206.3 \pm 18.3$ \\
\hline
\end{tabular}

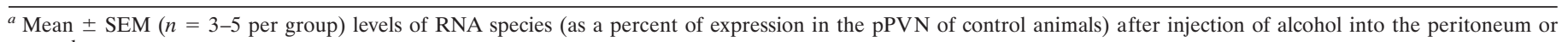
stomach.

${ }^{b}$ Statistical comparison was accomplished by two-way ANOVA with route of alcohol administration and time after injection as the variables.

${ }^{c}$ ND, Not determined.

of $4 \times \mathrm{SSC}(20 \times \mathrm{SSC}=3 \mathrm{M} \mathrm{NaCl}$ and $0.3 \mathrm{~m}$ citric acid, $\mathrm{pH} 7.0)$. Sections were digested in RNase A $(20 \mu \mathrm{g} / \mathrm{ml})$ at $37^{\circ} \mathrm{C}$, for $30 \mathrm{~min}$, washed in decreasing concentrations of $\operatorname{SSC}(2,2,1$, and $0.5 \times$ for $5 \mathrm{~min}$ each), washed in $0.1 \times \mathrm{SSC}\left(60^{\circ} \mathrm{C}\right.$ for $\left.30 \mathrm{~min}\right)$, and dehydrated through an alcohol series $(50,70,95,100$, and $100 \%, 3 \mathrm{~min}$ each). Sections were dried under vacuum and exposed on x-ray film (1-3 d; Biomax, Eastman Kodak, Rochester, NY), defatted in xylenes, and dipped in nuclear emulsion (NTB2 diluted 1:1 in distilled water, Kodak). Slides were then exposed for $10 \mathrm{~d}-6$ weeks and developed (D19, Kodak; $15^{\circ} \mathrm{C}$ for $3.5 \mathrm{~min}$ ), fixed (Kodak; $15^{\circ} \mathrm{C}$ for $6 \mathrm{~min}$ ), rinsed, counterstained with thionin $(0.25 \%)$, dehydrated through an alcohol series $(95,100$, and 100\%, 3 min each), cleared with xylenes, and coverslipped with DPX.

Because of the number of samples generated, in situ hybridization was done in two parts for each probe, segregated by injection route to maximize detection of temporal changes. However, we also included brain tissues within each batch that were known to express transcripts of the RNA to be measured (slides from animals treated with alcohol intraperitoneally in a separate experiment; positive control) to ensure that the absence of signal in some groups was not attributable to failed hybridization. In addition, we prolonged exposure times such that we were able to detect very low in situ hybridization signal.

Semiquantitative analysis of in situ hybridization results. Densitometric analysis of hybridization signals for c-fos mRNA, CRF hnRNA, and AVP hnRNA was performed in nuclear emulsion-dipped slides. The mean optical density (OD) of hybridization signal was measured under dark-field illumination using a Leitz (Wetzlar, Germany) optical system coupled with a Macintosh Power PC and Image software (version 1.60; W. Rasband, National Institutes of Health). Under bright-field illumination, first the parvocellular (pPVN) subdivision of the PVN (Swanson and Sawchenko, 1983; Ogilvie et al., 1997b) was traced using the drawing tool. Without moving the microscope stage, illumination was switched to dark-field, the tracing was restored over the image, and an OD measurement was taken. The tracing was then moved to a surrounding part of the tissue section, and a background measurement was taken. All measurements were corrected for background signal. After quantitating the signal from the pPVN, the process was repeated for the magnocellular division of the PVN (mPVN). Data were expressed in gray scale values of 1-256. Signals were measured on both sides of the brain, over 2-3 levels of the PVN ranging approximately from 1.5 to $2.1 \mathrm{~cm}$ posterior to bregma (Paxinos and Watson, 1986). Specific signal was averaged for each animal before statistical analysis of results. Data from four animals (two each route at $240 \mathrm{~min}$ after injection) were removed.

Statistical analysis. Levels of hybridization were subject to two-way ANOVA with route of injection (intraperitoneal vs intragastric) and time as the variables. Post hoc analysis was accomplished using the least squares means test.

\section{RESULTS}

\section{Expression of c-fos mRNA and Fos protein}

There was a significant effect of the route of alcohol injection on expression of c-fos mRNA in the pPVN ( $p=0.0027)$, as well as significant changes in mRNA levels over time $(p=0.0124)$. After intraperitoneal injection of alcohol, levels of pPVN c-fos mRNA were already significantly elevated within $10 \mathrm{~min}$ and peaked 60 min after injection, at which time expression of c-fos mRNA was 35 -fold higher than in noninjected controls (1.10 \pm 0.62 OD units; Table 1, Fig. 1). Levels of c-fos mRNA continued to be elevated in the pPVN of these rats for the duration of the experiment (240 min). In contrast, rats injected with alcohol intragastrically had two smaller rises in c-fos mRNA levels $(\sim 10$-fold over a control value of $1.29 \pm 0.80$ OD units), with the greatest levels detected 30 and $240 \mathrm{~min}$ after injection. In the mPVN, expression of c-fos mRNA was not significantly increased over control values of $3.31 \pm 1.51$ (intraperitoneal) or $1.38 \pm 0.68$ (intragastric) OD units by exposure to alcohol via either route $(p=0.3881)$, nor did levels change over time $(p=0.3414)$.

Congruent with the results for c-fos mRNA, Fos protein was robustly increased in the pPVN after intraperitoneal injection of alcohol (Fig. 1). Maximal activation, involving cells throughout the pPVN, was observed at $120 \mathrm{~min}$ after injection and persisted until $240 \mathrm{~min}$ after alcohol. We also observed a few cells that contained Fos in the pPVN of rats injected intragastrically with the drug 60 min before killing. 

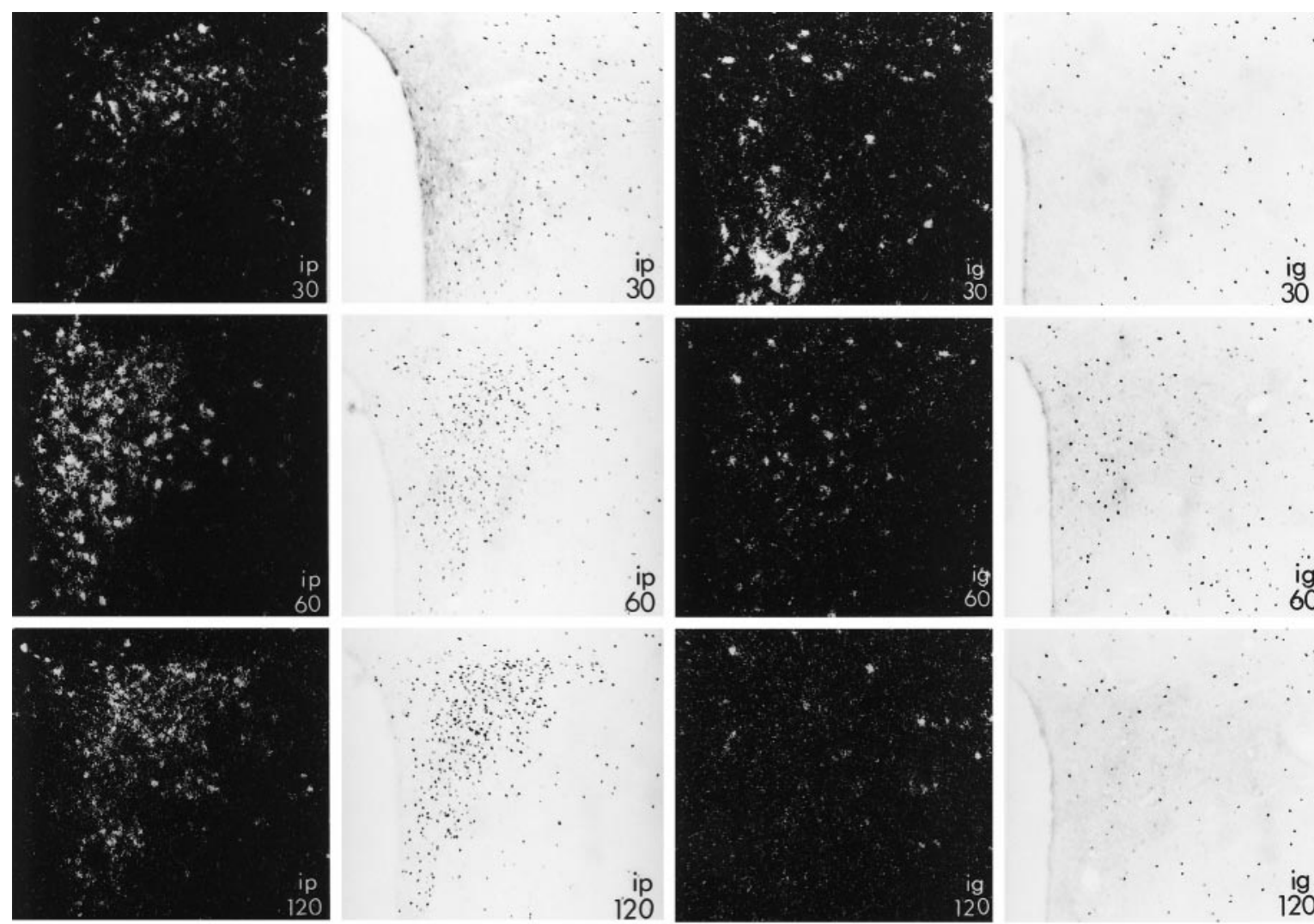

30
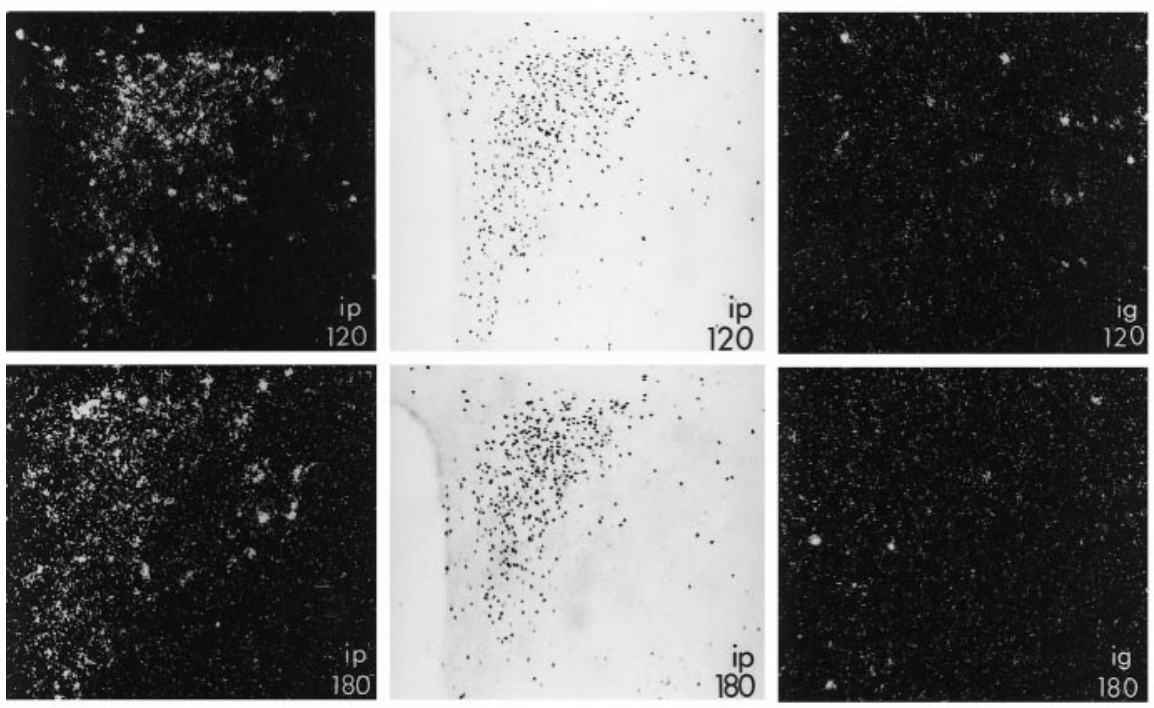

60
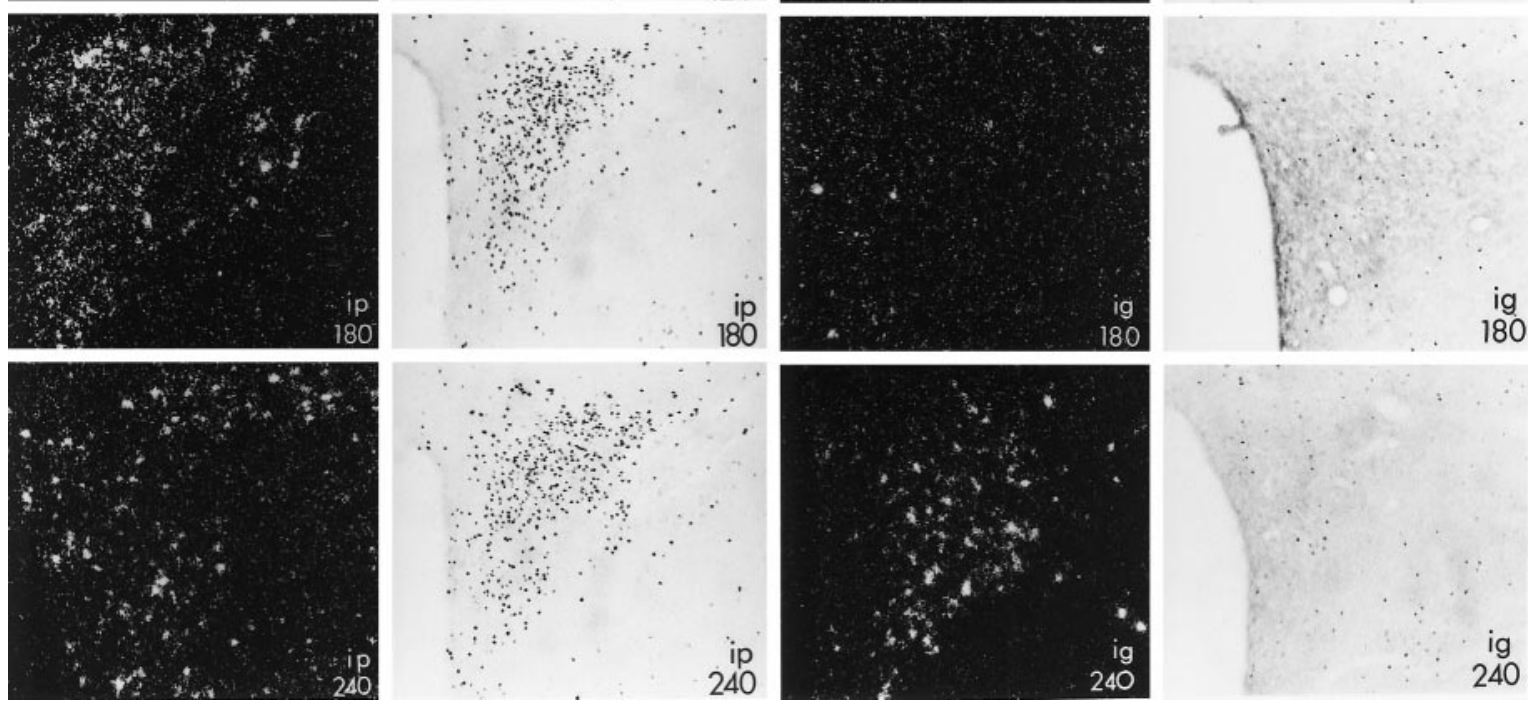

ig

Figure 1. Expression of c-fos mRNA (dark-field photomicrographs) and Fos protein (bright-field photomicrographs) in the paraventricular nucleus of male rats injected with alcohol intraperitoneally (left panels, ip) or intragastrically (right panels, ig) at the times indicated (in minutes). Note that in contrast to the robust activation in response to the drug administered intraperitoneally, rats that received alcohol into the stomach had only small elevations in c-fos mRNA (at 30 and $240 \mathrm{~min}$ ) and expressed Fos protein only in scattered cells (at 60 min). Magnification, 145×.

\section{Expression of CRF hnRNA}

There was a significant effect of the route of alcohol injection on expression of CRF hnRNA in the pPVN $(p=0.0060)$, as well as significant changes in transcript levels over time $(p=0.0002)$. As we have described previously, constitutive levels of CRF hnRNA in the pPVN are very low (intraperitoneal controls, $1.13 \pm 0.71$ OD units; intragastric controls, $1.83 \pm 0.94$ OD units) but readily induced by intraperitoneal injection of alcohol (Rivier and Lee,
1996). Indeed, levels are doubled by $30 \mathrm{~min}$ after injection and further increased at $60 \mathrm{~min}$ (Table 1, Fig. 2). In animals injected with alcohol intragastrically, however, no induction of CRF hnRNA was detectable at any of these time points. As was the case for the pPVN, CRF hnRNA expression in the mPVN was low (intraperitoneal controls, $0.67 \pm 0.67$ OD units; intragastric controls, $0.90 \pm 0.49$ OD units) and was significantly effected by route of alcohol injection $(p=0.0330)$, reflecting the higher 

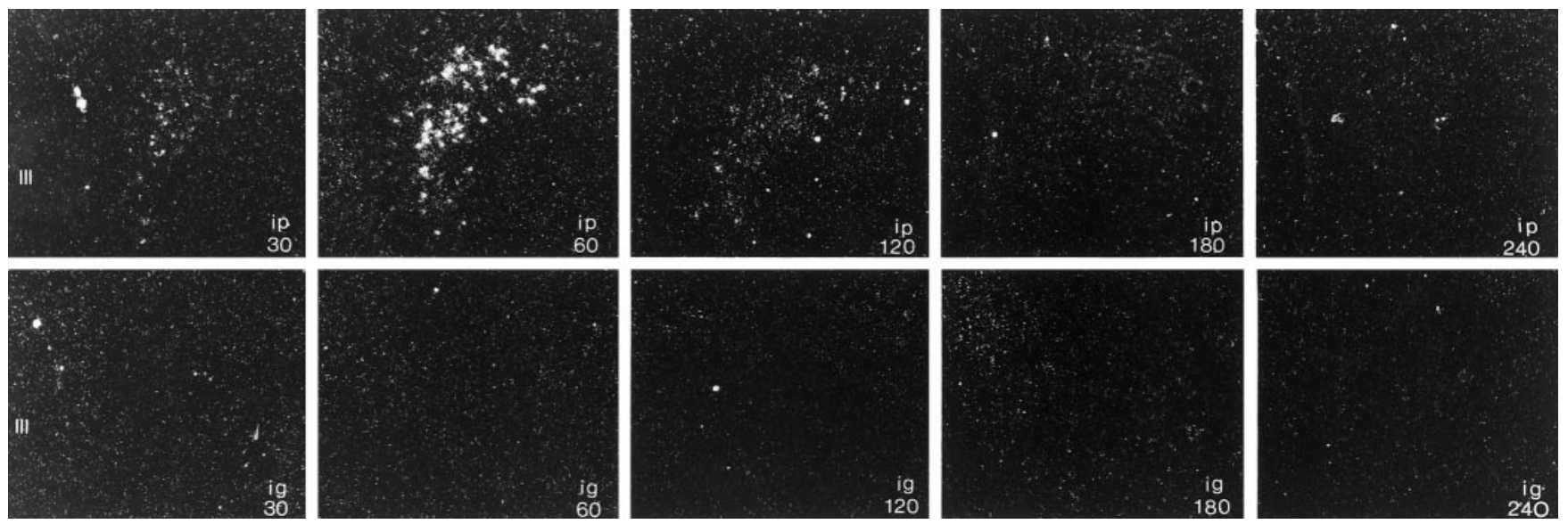

Figure 2. Expression of CRF hnRNA in the paraventricular nucleus of male rats injected with alcohol intraperitoneally (top) or intragastrically (bottom) at the times indicated (in minutes). Note that CRF hnRNA was expressed robustly in animals injected intraperitoneally, whereas levels were not detectable in rats that received alcohol intragastrically. Magnification, $130 \times$.
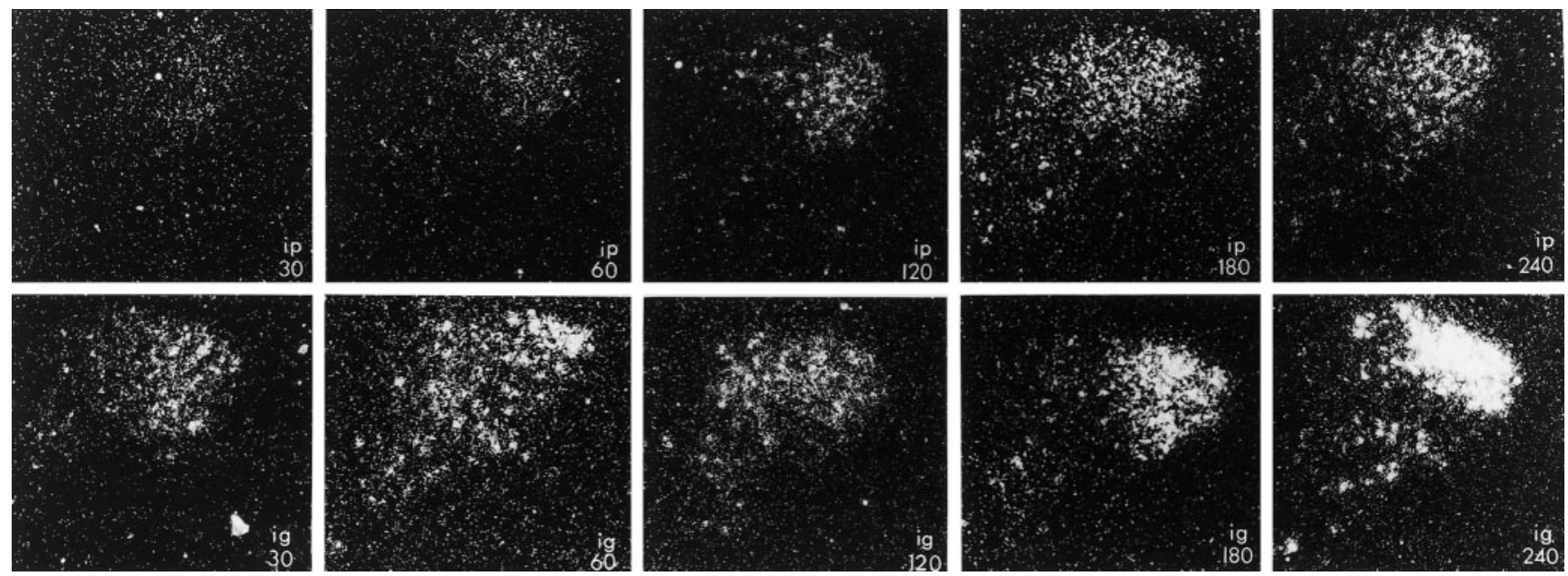

Figure 3. Expression of AVP hnRNA in the paraventricular nucleus of male rats injected with alcohol intraperitoneally (top) or intragastrically (bottom) at the times indicated (in minutes). Note that expression of AVP hnRNA in the parvocellular portion of the nucleus increased over time, regardless of the route of injection. Magnification, $130 \times$.

measurements obtained in animals injected with the drug intraperitoneally.

\section{Expression of AVP hnRNA}

Although initially suppressed after intraperitoneal injection of alcohol, levels of AVP hnRNA in the pPVN were elevated by administration of alcohol $(p=0.0402)$ via either route $(p=$ 0.0125 ), with the highest level of expression measured at $180 \mathrm{~min}$ (Table 1, Fig. 3). There was no interaction of these two variables ( $p=0.6172)$, indicating that the time course of the response was similar regardless of route of injection. Constitutive expression of AVP hnRNA was greater in the mPVN than in the pPVN, reflecting the larger number of cells in this area of the nucleus that synthesize this peptide (Sawchenko et al., 1984). Similar to the response within the pPVN, levels of AVP hnRNA were increased by exposure to alcohol via either route $(p=0.0124)$. However, in rats treated with the drug intragastrically, this response appeared to peak later (Table $1 ; p=0.0048$ ). Although it appears that activation may have been less robust in animals injected with the drug intraperitoneally, we cannot draw this conclusion, because in situ hybridization was performed separately in intragastric and intraperitoneally treated animals (see Materials and Methods) (intraperitoneal control: pPVN, $1.02 \pm$ $0.65 \mathrm{OD}$ units; $\mathrm{mPVN}, 6.67 \pm 1.44 \mathrm{OD}$ units; intragastric control: pPVN, $2.58 \pm 0.02$ OD units; mPVN, $12.23 \pm 2.89$ OD units).

\section{Summary of data}

Figure 4 summarizes all of our data on the expression of IEGs, CRF hnRNA, and AVP hnRNA in the pPVN after administration of alcohol intraperitoneally or intragastrically. In response to elevated BALs, male rats injected with the drug via either route secrete comparable amounts of ACTH over a similar time course (Ogilvie et al., 1997a). Coordinated with these events in peripheral circulation, expression of AVP hnRNA and NGFI-B mRNA (Ogilvie et al., 1997a) are increased in the pPVN. However, elevated CRF hnRNA is absent in animals injected with alcohol intragastrically. Furthermore, expression of c-fos mRNA and protein is weak and abbreviated after this route of injection. 


\section{intraperitoneal administration}

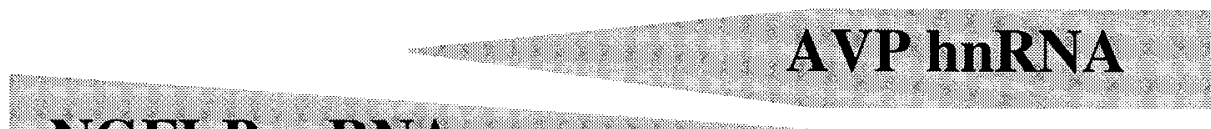

NGFI-B mRNA

CRF hnRNA

Fos protein

\section{c-fos mRNA}

\section{elevated ACTH}

elevated blood alcohol

$\begin{array}{lll}0 & 30 & 60\end{array}$

120

180

240

Time (min.)

\section{intragastric administration}

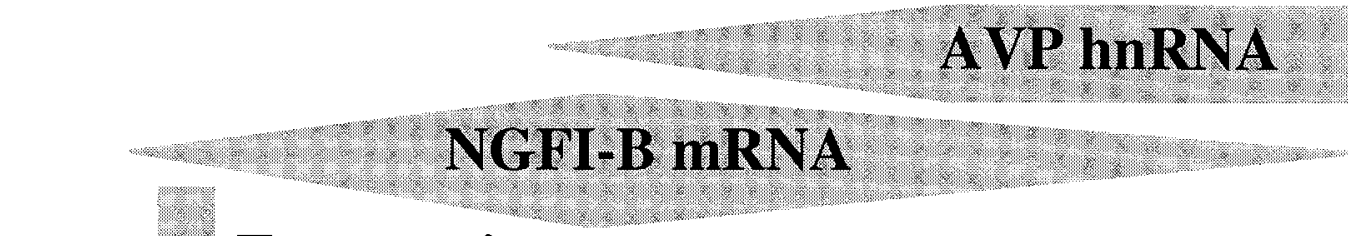

\section{Fos protein}

c-fos mRNA

c-fos mRNA

\section{elevated ACTH}

elevated blood alcohol

\begin{tabular}{llcccc}
\hline 0 & 30 & 60 & 120 & 180 & 240 \\
& & & Time (min.) & &
\end{tabular}




\section{DISCUSSION}

We show here that upregulated primary transcription of CRF (as indicated by elevated expression of hnRNA) is accompanied by robust increases in c-fos mRNA and Fos proteins throughout the parvocellular PVN of rats injected with alcohol intraperitoneally. This contrasted with results obtained in animals treated with the drug intragastrically, which showed no increase in CRF hnRNA and significantly less expression of c-fos mRNA or its protein. These results indicate that the activation of c-fos and CRF gene expression might be closely linked. Because expression of c-fos mRNA precedes demonstrable increases in CRF hnRNA in this model, an observation also made after other homeostatic threats (Imaki et al., 1992), it is possible that Fos protein might act to increase transcription of CRF. However, the promoter region of the CRF gene lacks an AP1 site (Thompson et al., 1990) to which Fos must bind, rendering this type of direct interaction improbable. Therefore, it appears likely that both CRF hnRNA and c-fos mRNA expression are induced in parallel rather than interacting with one another. As has been suggested previously, cAMPdependent systems might mediate this activation, because both CRF (Sassone-Corsi et al., 1988; Seasholtz et al., 1988) and c-fos (Sassone-Corsi et al., 1988) bear functional cAMP response elements (Kovács and Sawchenko, 1996b).

We have previously shown that levels of NGFI-B mRNA were elevated after alcohol injection regardless of route of injection in these same animals (Ogilvie et al., 1997a). This is an important observation, because the robust expression of this IEG in response to a variety of stimuli that activate the HPA (Chan et al., 1993; Rivest and Rivier, 1994; Rivier and Lee, 1996), coupled with the presence of an NBRE on the CRF promoter, suggest a substrate for activation of CRF gene transcription by NGFI-B. However, two observations argue against this functional relationship. First, the expression of NGFI-B mRNA lagged behind the expression of CRF hnRNA in animals injected with alcohol intraperitoneally. Second, NGFI-B mRNA is also elevated in animals injected with the drug intragastrically, in which levels of CRF hnRNA do not significantly rise. This is an indication that NGFI-B expression is not well correlated with the appearance of either CRF hnRNA or c-fos mRNA in alcohol-treated rats. Despite the presence of an AP1 site on the NGFI-B promoter (Watson and Milbrandt, 1989), our data also confirm an earlier conclusion that Fos protein expression is not necessary for transcription of NGFI-B (Rivest and Rivier, 1994). However, the timing of NGFI-B mRNA expression was temporally correlated with the appearance of AVP hnRNA. Because AVP contains a putative NBRE, it is thus possible that NGFI-B regulates expression of this gene. We must nevertheless point out that NGFI-B mRNA is present in many cells in the pPVN but is sparsely expressed in the mPVN (Ogilvie et al., 1997a), whereas AVP hnRNA is confined to a few scattered cells in the pPVN and is detectable over the entire mPVN (this study). Therefore, the extent to which NGFI-B might contribute to the transcription of AVP and the identity of the cells in which this interaction might be important remain to be determined.
Distinct combinations of IEGs are thought to confer specificity in the cellular response to different stimuli, and there are known differences in the kinetics and the magnitude of responses (Sheng and Greenberg, 1990). For example, differential expression of fos and jun mRNA families have been found in rats exposed to immobilization stress (Senba et al., 1994). We show here that, indeed, there was a significant difference between the patterns of Fos and NGFI-B signals in response to alcohol. Additionally, we failed to observe transcriptional activation of CRF in animals injected with alcohol intragastrically, although we have routinely observed that the secretion of ACTH was comparable after either route of administration (Ogilvie et al., 1997a). Not only did we use positive controls during in situ hybridization to ensure that our results were not attributable to failed hybridization, we also replicated this experiment, thereby confirming the lack of CRF activation and correlating it with sparse c-fos mRNA and Fos protein expression. Although we had not expected this result, it is not particularly surprising given that injection of interleukin $1 \beta$ via different routes (intravenously vs intracerebroventricularly) (Rivest et al., 1992), for example, also induces a differential pattern of Fos protein expression in the PVN despite their ability to induce similar increases in ACTH secretion. In addition, it should be noted that the dynamics of alcohol exposure differs after the two routes of administration (see Materials and Methods), with greater peak levels attained after intraperitoneal injection. Although this difference in expression of cellular markers may be indicative of a reliance on alternate pathways to ACTH secretion, our data suggest that a lack of Fos expression does not preclude cellular activation, because the IEG NGFI-B is expressed throughout the pPVN in rats injected with alcohol intragastrically. Indeed, although Fos expression is well correlated with many endocrine and behavioral indices of stress, including those directly connected with CRF-activated pathways (Imaki et al., 1992; Parkes et al., 1993; Rivest and Rivier, 1994), it is also apparent that the expression of Fos in the pPVN is not obligatory to HPA function (Rivest et al., 1992; this study). In other systems as well, Fos activation is neither necessary (Mead et al., 1992) nor sufficient (Rea et al., 1993; Sladek and Olschowka, 1994; Kovács and Sawchenko, 1996a; Le et al., 1997) for neuroendocrine function.

In conclusion, our data show parallel activation of c-fos mRNA, Fos protein, and CRF hnRNA in male rats injected with alcohol intraperitoneally, suggesting that these cellular events may depend on the same primary phenomenon (possibly increased cAMP). On the other hand, expression of NGFI-B throughout the pPVN took place in all animals injected with alcohol, regardless of route. This latter finding confirms that cellular activation in the pPVN had occurred, despite the lack of robust increases in CRF hnRNA, c-fos mRNA, and Fos protein in rats that received the drug intragastrically. This demonstrates the requirement for careful interpretation of IEG data, especially when induction is not manifest. For instance, had we only examined expression of NGFI-B, we would have concluded that alcohol stimulated hypothalamic activity in a similar manner, regardless of route of

\footnotetext{
Figure 4. Summary of the temporal activation of hypothalamic-pituitary-adrenal axis in male rats injected intraperitoneally (top) or intragastrically (bottom) with alcohol. Gray polygons indicate the duration of detectable increases in the measure, whereas the widest portion of the polygon indicates the time at which peak levels were attained. In response to rising blood alcohol levels, ACTH is released from the anterior pituitary. Although the secretion of ACTH is of similar magnitude and duration after either route of injection, alcohol-induced activation of CRF hnRNA in the parvocellular division of the paraventricular nucleus of the hypothalamus ( $\mathrm{pPVN}$ ) is only observed in rats that received the drug intraperitoneally. Furthermore, in rats injected with alcohol intragastrically, expression of the c-fos mRNA and Fos protein is confined to a few cells in the pPVN and is abbreviated in comparison to animals injected intraperitoneally.
} 
administration. In contrast, reliance on either c-fos mRNA or Fos protein expression alone would have suggested that alcohol given intragastrically did not result in cellular activation at the level of the pPVN. Taken together, however, our data indicate that alcohol can evoke ACTH secretion via at least two mechanisms, both of which effect neurons in the pPVN.

\section{REFERENCES}

Antoni FA (1986) Hypothalamic control of adrenocorticotropin secretion: advances since the discovery of 41-residue corticotropin-releasing factor. Endocr Rev 7:351-378.

Chan RKW, Brown ER, Ericsson A, Kovács KJ, Sawchenko PE (1993) A comparison of two immediate-early genes, c-fos and NGFI-B, as markers for functional activation in stress-related neuroendocrine circuitry. J Neurosci 13:5126-5151.

Chang SL, Patel NA, Romero AA, Kenig V (1994) Ethanol induces FOS immunoreactivity in the rat brain. Regul Pept 54:51-52.

Day HEW, Akil H (1996) Differential pattern of c-fos mRNA in rat brain following central and systemic administration of interleukin-1beta: implications for mechanism of action. Neuroendocrinology 63:207-218.

Doucet JP, Squinto SP, Bazan NG (1990) Fos-jun and the primary genomic response in the nervous system. Mol Neurobiol 4:27-55.

Dragunow M, Faull R (1989) The use of c-fos as a metabolic marker in neuronal pathway tracing. J Neurosci Methods 29:261-265.

Hoffman GE, Smith MS, Verbalis JG (1993) c-fos and related immediate early gene products as markers of activity in neuroendocrine systems. Front Neuroendocrinol 14:173-213.

Imaki T, Shibasaki T, Hotta M, Demura H (1992) Early induction of c-fos precedes increased expression of corticotropin-releasing factor messenger ribonucleic acid in the paraventricular nucleus after immobilization stress. Endocrinology 131:240-246.

Kinoshita H, Ijiri I, Ameno S, Fuke C, Ameno K (1995) Additional proof of reduction of ethanol absorption from rat intestine in vivo by high acetaldehyde concentrations. Alcohol Alcohol 30:419-421.

Kovács KJ, Sawchenko PE (1996a) Regulation of stress-induced transcriptional changes in the hypothalamic neurosecretory neurons. J Mol Neurosci 7:125-133.

Kovács KJ, Sawchenko PE (1996b) Sequence of stress-induced alterations in indices of synaptic and transcriptional activation in parvocellular neurosecretory neurons. J Neurosci 16:262-273.

Le WW, Berghorn KA, Smith MS, Hoffman GE (1997) Alpha(1)adrenergic receptor blockade blocks $\mathrm{LH}$ secretion but not LHRH cFos activation. Brain Res 747:236-245.

Lee S, Rivier C (1994) Interaction between alcohol and interleukin-1B on ACTH secretion and the expression of immediate early genes in the hypothalamus. Mol Cell Neurosci 5:442-450.

Lee S, Rivier C (1997) An initial, three-day-long treatment with alcohol induces a long-lasting phenomenon of selective tolerance in the activity of the rat hypothalamic-pituitary-adrenal axis. J Neurosci 17:8856-8866.

Lee S, Rivier C (1998) Interaction between corticotropin-releasing factor, vasopressin and nitric oxide in mediating the response of the rat hypothalamus to immune and non-immune stimuli. Mol Brain Res, in press.

Maier SE, Strittmatter MA, Chen WJA, West JR (1995) Changes in blood alcohol levels as a function of alcohol concentration and repeated alcohol exposure in adult female rats: potential risk factors for alcohol-induced fetal brain injury. Alcohol Clin Exp Res 19:923-927.

Mead S, Ebling FJP, Maywood ES, Humby T, Herbert J, Hastings MH (1992) A nonphotic stimulus causes instantaneous phase advances of the light-entrainable circadian oscillator of the Syrian hamster but does not induce the expression of c-fos in the suprachiasmatic nuclei. J Neurosci 12:2516-2522.

Mohr E, Richter D (1990) Sequence analysis of the promoter region of the rat vasopressin gene. FEBS Lett 260:305-308.

Morgan JI, Curran T (1989) Stimulus-transcription coupling in neurons: role of cellular immediate-early genes. Trends Neurosci 12: $459-462$.
Morgan JI, Curran T (1991) Stimulus-transcription coupling in the nervous system: involvement of the inducible proto-oncogenes fos and jun. Annu Rev Neurosci 14:421-451.

Ogilvie KM, Rivier C (1996) Gender difference in alcohol-evoked hypothalamic-pituitary-adrenal activity in the rat: ontogeny and role of neonatal steroids. Alcohol Clin Exp Res 20:255-261.

Ogilvie KM, Rivier C (1997) Effect of alcohol on the proestrous surge of luteinizing hormone $(\mathrm{LH})$ and the activation of LH-releasing hormone (LHRH) neurons in the female rat. J Neurosci 17:2595-2604.

Ogilvie K, Lee S, Rivier C (1997a) Effect of three different modes of alcohol administration on the activity of the rat hypothalamic-pituitary-adrenal axis. Alcohol Clin Exp Res 21:467-476.

Ogilvie KM, Lee S, Rivier C (1997b) Role of vasopressin (AVP) and corticotropin-releasing factor in mediating alcohol-induced ACTH and AVP secretion in male rats bearing lesions of the paraventricular nuclei. Brain Res 744:83-95.

Parkes D, Rivest S, Lee S, Rivier C, Vale W (1993) Corticotropinreleasing factor activates c-fos, NGFI-B, and corticotropin-releasing factor gene expression within the paraventricular nucleus of the rat hypothalamus. Mol Endocrinol 7:1357-1367.

Paxinos G, Watson C (1986) The rat brain in stereotaxic coordinates, Ed 2. San Diego: Academic.

Rea MA, Michel AM, Lutton LM (1993) Is Fos expression necessary and sufficient to mediate light-induced phase advances of the suprachiasmatic circadian oscillator? J Biol Rhythms 8:S59-S64.

Rivest S, Rivier C (1994) Stress and interleukin- $1 \beta$-induced activation of c-fos, NGFI-B and CRF gene expression in the hypothalamic PVN: comparison between Sprague-Dawley, Fisher-344 and Lewis rats. J Neuroendocrinol 6:101-117.

Rivest S, Torres G, Rivier C (1992) Differential effects of central and peripheral injection of interleukin- $B$ on brain c- fos expression and neuroendocrine functions. Brain Res 587:13-23.

Rivier C (1996) Alcohol stimulates ACTH secretion in the rat: Mechanisms of action and interactions with other stimuli. Alcohol Clin Exp Res 20:240-254.

Rivier C, Lee S (1995) Stimulatory influence of EtOH on ACTH secretion: role of vasopressin and corticotropin-releasing factor. Soc Neurosci Abstr 21:546.9.

Rivier C, Lee S (1996) Acute alcohol administration stimulates the activity of hypothalamic neurons that express corticotropin-releasing factor and vasopressin. Brain Res 726:1-10.

Rivier C, Plotsky PM (1986) Mediation by corticotropin-releasing factor (CRF) of adenohypophysial hormone secretion. Annu Rev Physiol 48:475-494.

Rivier C, Bruhn T, Vale W (1984) Effect of ethanol on the hypothalamic-pituitary-adrenal axis in the rat: role of corticotropin-releasing factor (CRF). J Pharmacol Exp Ther 229:127-131.

Ryabinin AE, Criado JR, Henriksen SJ, Bloom FE, Wilson MC (1997) Differential sensitivity of c-Fos expression in hippocampus and other brain regions to moderate and low doses of alcohol. Mol Psychiatry 2:32-43.

Sagar SM, Sharp FR, Curran T (1988) Expression of c-fos protein in brain: metabolic mapping at the cellular level. Science 240:1328-1331.

Sassone-Corsi P, Visvader J, Ferland L, Mellon PL, Verma IM (1988) Induction of the proto-oncogene fos transcription through the adenylate cyclase pathway: characterization of a cAMP-responsive element. Genes Dev 2:1529-1538.

Sawchenko PE, Swanson LW, Vale WW (1984) Corticotropin-releasing factor: co-expression within distinct subsets of oxytocin-, vasopressinand neurotensin-immunoreactive neurons in the hypothalamus of the male rat. J Neurosci 4:1118-1129.

Seasholtz AF, Thompson RC, Douglass JO (1988) Identification of a cycle adenosine monophosphate-responsive element in the rat corticotropin-releasing hormone gene. Mol Endocrinol 2:1311-1319.

Senba E, Umemoto S, Kawai Y, Noguchi K (1994) Differential expression of fos family and jun family mRNAs in the rat hypothalamopituitary-adrenal axis after immobilization stress. Mol Brain Res 24:283-294.

Sheng M, Greenberg ME (1990) The regulation and function of c-fos and other immediate early genes in the nervous system. Neuron 4:477485. 
Simmons DM, Arriza JL, Swanson LW (1989) A complete protocol for in situ hybridization of messenger RNAs in brain and other tissues with radiolabeled single-stranded RNA probes. J Histotechnol 12:169-181.

Sladek CD, Olschowka JA (1994) Dehydration induces Fos, but not increased vasopressin mRNA in the supraoptic nucleus of aged rats. Brain Res 652:207-215.

Swanson LW, Sawchenko PE (1983) Hypothalamic integration: organization of the paraventricular and supraoptic nuclei. Annu Rev Neurosci 6:269-324.

Thompson RC, Seasholtz AF, Douglass JO, Herbert E (1990) Cloning and distribution of expression of the rat corticotropin-releasing factor (CRF) gene. In: Corticotropin-releasing factor: basic and clinical stud- ies of a neuropeptide (De Souza EB, Nemeroff CB, eds), pp 1-12. Boca Raton, FL: CRC.

Watson MA, Milbrandt J (1989) The NGFI-B gene, a transcriptionally inducible member of the steroid receptor gene superfamily: genomic structure and expression in rat brain after seizure induction. Mol Cell Biol 9:4213-4219.

Wilson TE, Fahrner TJ, Johnston M, Milbrandt J (1991) Identification of the DNA binding site for NGFI-B by genetic selection in yeast. Science 252:1296-1300.

Zoeller RT, Fletcher DL (1994) A single administration of ethanol simultaneously increases c-fos mRNA and reduces c-jun mRNA in the hypothalamus and hippocampus. Mol Brain Res 24:185-191. 